\title{
Game Theory and Environmental and Resource Economics-In Honour of Alfred Endres
}

\author{
Michael Finus $^{1}$ - Bianca Rundshagen ${ }^{2}$
}

Published online: 26 August 2015

C Springer Science+Business Media Dordrecht 2015

This special issue is devoted to Alfred Endres, on the occasion of his 65th birthday in 2015, as a tribute to his fundamental contributions to the field environmental and resource economics.

Endres earned his diploma (equivalent to Master) in Economics from the University of Bonn in 1973 and his PhD from the University of Dortmund in 1976. In 1981 he earned his habilitation from the University of Constance. In 1982, Endres was appointed to the new and first chair in Environmental Economics in Germany at the Technical University of Berlin. Currently, Alfred Endres is Full Professor of Economics at the University of Hagen and Permanent Visiting Professor of Environmental Economics at the University of Witten/Herdecke. He held visiting appointments at the University of California, San Diego and La Trobe University, Melbourne and has also taught at the Bosphorus University, Istanbul, Zhejiang University at Hangzhou and the State University of New York at Buffalo. He is the author of numerous journal articles and 14 books on Environmental Economics, Applied Economics and Microeconomics, among those his intermediate textbook "Environmental Economics-Theory and Policy" published by Cambridge University Press (Endres 2011).

At a time when environmental regulation was essentially based on command and control instruments, Endres wrote his dissertation on the internalization of environmental externalities using negotiations and taxes (Endres 1976). He soon became well-known for his contributions on the Coase-Theorem and market-based environmental policy instruments, including permit trading (Endres 1977a,b, 1983, 1986; Braulke and Endres 1985). Ironically, one of his most innovative early papers (Endres 1985) was published in a hardly accessible volume of collected articles, which may explain that it was overlooked by the subsequent literature. Endres presented a pioneering analysis on the economics of interacting pollutants.Many years later, Kuosmanen and Laukkanen (2011) rediscovered the article and highlighted its seminal character.

Michael Finus

M.Finus@bath.ac.uk

1 Department of Economics, University of Bath, Bath, UK

2 Institute of Economic Theory, University of Hagen, Hagen, Germany 
One major research strand in Alfred Endres' work relates to the economic analysis of law. He published papers on product liability, tort law and incomplete information (Endres 1989, 1991a, 1992; Endres and Querner 1995; Endres and Lüdeke 1998, 1999). This general analysis was extended to environmental economics where Endres paid special attention to the analysis of environmental liability law (Endres 1991b; Endres and Friehe 2012, 2015). His contributions to this area closed an important and surprising gap in the literature. On the one hand, environmental law plays a fundamental role in actual environmental policy making. On the other hand, it is usually neglected in the environmental economics literature, which is also evident from numerous textbooks on the subject.

A second major research strand and very much related to the theme of this special issue combines game theoretic and microeconomic approaches to analyse transboundary pollution. Endres was one of the pioneers in analysing the conditions for the implementation of efficient international environmental agreements. He introduced the concept of noncooperative international bargaining according to the smallest common denominator rule (Endres 1997). Endres was convinced that the typical bargaining solutions available in game theory are ill-suited to capture typical characteristics of actual international negotiations. In order to improve our understanding of actual treaty-making, and to contribute to a positive analysis of actual negotiations, he modelled negotiations as a Walrasian auction process in which governments make selfish and strategic proposals. He found two features important. First, international agreements are typically reached by unanimous consensus, reflecting the agreement on the smallest common denominator. Second, policy instruments and bargaining solutions are not always efficient. Apart from a bargaining over a uniform emission tax, he considered uniform emission reduction quotas. He showed that those second-best solutions may achieve more than first-best solution if agreements are subject to free-riding. The reason is twofold. First, the agreed abatement target is lower than first-best solution, allowing more countries to join an environmental treaty. Second, uniform emission reduction quotas, though generally not cost-effective, lead to a more symmetric distribution of the gains from cooperation, again, allowing more countries to join an environmental treaty. In the research project "Cooperative Solutions for International Environmental Problems: An Economic Analysis Considering Public Choice Aspects" he continued this line of research with Michael Finus (Endres and Finus 1998a, b, 1999, 2002) with follow-up publications (Finus 2001; Finus and Rundshagen 1998a,b) along the same lines. For instance, it was shown that similar results can be obtained for negotiations on the initial allocation of permits. Moreover, it was demonstrated that this bargaining process is robust against strategic proposals and that stability of large effective coalitions are not only obtained for coalition models but also in repeated games with renegotiation-proof implementation strategies.

In the research project "Human Dimensions of Global Environmental Change: Integrating Risk and Strategic Aspects in the Economic Analysis of Global Environmental Problems" he applied a risk-strategic approach to international cooperation. This combined game-theoretic and risk economic methods to explain the possibility of international co-operation in terms of objective and subjective risk assessment. Given the intensity of (country-specific) risk aversion he showed that the prospects of co-operation varies by the choice of national policy instruments and technology. Both factors determine the objective risk parameters. To highlight their influence on the success of global risk management, he developed a new criterion for international policy assessment and choice: "the criterion of co-operative push" (Endres and $\mathrm{Ohl} 2002,2003)$. The inclusion of uncertainty and risk in agreement formation inspired a couple of papers much later on, like Boucher and Bramoullé (2010), Bramoullé and Treich (2009), and Hong and Karp (2013). 
A third and more recent line of research of Alfred Endres is the analysis of induced technical change through environmental policy instruments. Issues like the invention and diffusion of environmentally friendly technologies are considered with a particular focus on environmental liability law. In particular, Alfred Endres analyses how different liability rules, like strict liability and negligence rule, perform with respect to their dynamic incentives, considering different sources of market failures (Endres and Bertram 2006; Endres et al. 2007; Endres and Friehe 2011). Endres and his co-authors were the first who analysed the incentives of environmental liability law for investments into environmentally friendly technological change and the diffusion of green technology. This work opened up the intellectual space for a completely new area of research. In the recent literature, this approach was followed by contributions like Jacob (2015) and Korsmo (2015), generalizing and extending the initial contributions by Endres. Even though in Endres' work on dynamic incentives there is an emphasis on environmental liability law, other environmental policy instruments, like effluent charges and transferable discharge permits, are also considered (Endres and Rundshagen 2010). The analysis spans from national policy issues to international environmental treaty making (Endres and Rundshagen 2013), which nicely demonstrates how all three research strands are linked, despite each of these strands is important in its own right.

Another paper of Endres worth mentioning, even though it does not deal with the economics of the environment, is Endres (1980). This paper deals with the economics of excludable public goods. It is the first paper which analyses the markets for information in which the buyers are able to costlessly diffuse information and process information in their production function. During the time before the internet, this may have been regarded as an ivory tower exercise. Decades later, the fundamental implications of this model for the economics of information and, very practically, for the problems of the publishing industry are very evident and relevant.

This special issue comprises some interesting papers which use game theory to analyse environmental and resource economic problems. Due to the huge number of submissions, the issue is split in two parts of which Volume I is published in 2015 and Volume II in 2016. This is Volume I. In the following, we give a short overview of the different contributions. Before doing so, it is worthwhile to briefly recall that the last three decades have seen an increasing use of game-theoretic tools in order to analyse market failures due to environmental externalities and the possibility to correct those through environmental policy instruments. This is not surprising: game theory analyses the strategic interaction among different agents and tries to predict the outcome of those interactions. Hence, game theory is particularly suited for analysing the incentive structure of agents to which they are exposed in incomplete markets, state regulation and weak international institutions in the context of environmental externalities.

The first set of papers deals with the analysis of international environmental agreements (IEAs) or international fishery agreements (IFAs). Due to the lack of a global enforcement authority, IEAs and IFAs have to be self-enforcing. Due to strong free-rider incentives, the design of stable and effective agreements is a challenging task. This has been the case when the first papers emerged in the early 1990s but continues to be a problem, which explains why still many papers are written on the subject. Broadly speaking, models can be classified into non-cooperative and cooperative game-theoretic approaches. The non-cooperative approach has proved to be particularly fruitful for a positive analysis of the formation and stability of IEAs and IFAs, even though many papers combine elements of both approaches. For instance, the analysis of the formation of equilibrium coalition structures typically assumes that coalition members maximize the aggregate welfare of all coalition members and assume 
that agreements are binding, which clearly has a cooperative spirit, but the decisions whether to join an agreement or remain outside are taken non-cooperatively.

In the first paper, Hovi et al. (2015) review the formal literature on models of international climate cooperation, mainly based on papers rooted in the economics tradition but also include some insights from political scientists, which broaden the perspective. In the first part of their paper they point out the rather pessimistic conclusions reached by the bulk of literature on coalitions, repeated games and some other approaches. They then ask the provocative question whether there is light at the end of the tunnel. Based on the theoretic literature in economics and political sciences, but also supported by real world evidence, they argue that even though mitigating free-rider incentives completely is difficult, they can be reduced substantially through various measures. Examples include for instance issue linkage of climate cooperation and R\&D cooperation, trade restrictions and sanctions, a deposit refund system in order to enhance the credibility of sanctions, trust and network approaches to increase linkages and reciprocity, decentralized forms of cooperation as well as transfers or minimum participation clauses. The article greatly benefits from the background of the authors who have all worked for a very long time on the subject and have roots in the economics as well as the formal political sciences literature.

The second paper by Pintassilgo et al. (2015) constitutes a survey, which reviews the expanding game-theoretic literature on international fishery agreements (IFAs). This strand of literature differs from the literature on IEAs, which mainly analyses agreements on greenhouse gases and other atmospheric global pollutants, by the following main characteristics. Fish stocks are a typical example of a renewable resource. Moreover, preservation of fish stocks constitutes an impure (and not a pure) public good as migration patterns matter for the exploitation of fish stocks as well as the establishment of property rights, at least in some regions, like exclusive economic zones. The distribution and migration of fish stocks determines the bargaining power of negotiating parties and can create a substantial asymmetry between players. This is also due to the fact that some fishing nations are without a coast and hence do not possess an exclusive economic fishing zone and hence need to act as distant water fishing nations. Pintassilgo et al. focus on non-cooperative game-theoretic coalition approaches but also consider some other approaches which have been relevant in this literature.

Weikard et al. (2015) analyse the effect of minimum participation rules (MPRs) on the effectiveness of IEAs. They generalize the model of Carraro et al. (2009) to heterogeneous countries and assume that the MPR is specified in terms of non-cooperative abatement levels. That is, the MPR is satisfied if the sum of the non-cooperative benchmark abatement levels of signatories exceeds an endogenously determined lower bound. (An alternative MPR could for instance specify a minimum number of signatories.) As in Carraro et al. (2009) the MPR is chosen according to a unanimity voting rule. Some arbitrary country proposes an MPR, which is implemented if and only if all countries agree to it. It is shown that MPRs strengthen cooperation, with stricter MPRs (in terms of benchmark abatement levels) outperforming weaker ones. If the MPR requires full participation, the grand coalition is stable. However, in case of heterogeneous countries, the equilibrium MPR may be lower such that partial free-riding cannot be prevented.

McEvoy et al. (2015) experimentally test an agreement formation game that also includes an endogenously determined MPR. For their purpose, they consider a simplified version of Carraro's et al. (2009) homogenous agent model. They consider a two-stage game where in the first stage participants vote on a MPR and in the second stage they decide whether they join the coalition. McEvoy et al. do not consider a typical positive externality game, which fulfils superadditivity. Instead, they allow for the possibility that an efficient public good 
provision level can be provided by a subcoalition. In other words, contributions to the public good yield a positive return only if the aggregate contributions do not exceed an upper bound. A possible application mentioned in the paper is that abatement activities only yield a positive marginal benefit as long as global emissions do not drop below the absorptive capacity of the natural environment. In the theoretical analysis, the equilibrium coalition size always equals the efficient one, irrespective whether this is the grand coalition or a sub-coalition. However, in the laboratory experiment it turns out that the prospects for efficient cooperation are higher when efficiency requires full cooperation, than in the case when efficiency requires only partial cooperation. This suggests that full cooperation may be viewed as a kind of focal point.

Bayramoglu and Jacques (2015) consider a transboundary pollution problem between two asymmetric countries and compare the outcomes of two bargaining regimes with respect to global and country-specific welfare. They compare a uniform abatement agreement with costly monetary transfers with a differentiated agreement without transfers. Bayramoglu and Jacques assume "a cooperative spirit in the agreement" and therefore compare the generalized Nash bargaining solution in these two regimes. They show that if transaction costs are sufficiently low, both countries prefer the uniform agreement over the differentiated one.

In contrast to the previously mentioned papers, Heuson et al. (2015) consider a strictly non-cooperative climate change game with non-cooperative choice of mitigation levels. They analyse the interplay of two strategic variables to influence mitigation efforts abroad. These two variables are investment in technical progress that reduces national mitigation cost and adaptation efforts which reduce national environmental damages for any given level of mitigation. Taking into account that investment takes place before mitigation, there are three possible sequences of investment, mitigation and adoption, which are all systematically analysed. It is shown that the sequence where adaption occurs before mitigation may reinforce the strategic effect of underinvestment in technology. Several measures are proposed in order to address the negative impact of strategic behaviour by governments.

Stephan and Müller-Fürstenberger (2015) analyse the question whether technology transfers from the North to the South may help to combat climate change even in the absence of a global climate treaty. They consider technology transfers of more energy-efficient technologies and assume that carbon energy is traded on a single integrated world market. It is shown that even under optimistic assumptions rebound and leakage effects contradict welfare improving solutions of the climate problem.

Lessmann et al. (2015) compare various numerically calibrated integrated assessment models of climate change mitigation which have been used for the game-theoretic analysis of agreement formation. The basic idea is to understand in which respects these models differ but also what they have in common. In particular, the authors attempt to highlight the differences in the underlying assumptions with respect to costs and benefits and to explain how this leads to different results. They show that the estimates for abatement potentials of world key regions are rather homogenous whereas there are substantial differences in the climate change damage estimates. The latter reflects the fact that there are still large uncertainties with respect to the benefits of climate change mitigation, respectively the damages from greenhouse gas concentration. Those differences in damage estimates imply different predictions about equilibrium coalitions, even though in general, results with respect to the incentive to sign an agreement are rather robust. Moreover, they show that transfer schemes have a huge potential to improve the effectiveness of IEAs.

Ochea and de Zeeuw (2015) use an evolutionary game theory approach to analyse the performance of tit-for-tat strategies in the evolution of cooperation in international environmental negotiations. Whereas in evolutionary game theory evolution is formalized as a 
Darwinian process of natural selection, i.e. the successful individuals have a higher fertility and bequeath their strategies to their descendants, Ochea and de Zeeuw consider countries that do not die but adjust their strategies when other strategies are more successful. In particular, they use replicator dynamics where the fractions of tit-for-tat strategies (compared to unconditional defection) increase if the performance of this strategy is better than average. They show that under certain circumstances full cooperative behaviour may be sustained. For this a particular critical mass of initial reciprocators is necessary. Ochea and de Zeeuw conclude that in the context of climate change, it may help if countries switch to a strategy of conditional cooperation instead of trying to reach a unanimous agreement.

Houba et al. (2015) analyse coalition formation and the strategic timing of joining an IEA. They apply the Coalitional Bargaining Game of Gomes (2005) to a river sharing problem with three agents and determine the Markov perfect equilibria. They show that the number of bargaining rounds depends on the parameter values and a grand coalition may emerge, even though a sub-coalition is the outcome of the first bargaining round.

The last four papers discuss various aspects of environmental policy instruments. The paper of Álvarez and Andre (2015) is about permit trading. They compare the effectiveness of the allocation rules auctioning and grandfathering, when firms have private information on their abatement technologies and there is a secondary market with market power where agents either act as a leader or follower. It turns out that under auctioning the leader may bid strategically in order to increase his market power in the secondary market. On the other hand, the allocation under auctioning incorporates information that is only privately observable. Hence, it depends on the relative strength of these two effects whether auctioning or grandfathering is more cost-effective. A departure from cost-effectiveness arises due to strategic behaviour in the permit market. That is, under auctioning the equilibrium is never cost-effective because the leader bids strategically, taking into account his position in the secondary market.

Dubois and Eyckmans (2015) analyse Extended Producer Responsibility (EPR) as a policy instrument of waste management. EPRs make producers financially responsible for the recycling of their products at the end of their life cycle. Formalizing a two-country model with imperfect competition in the recycling-market, they show that EPR alone cannot achieve first-best outcomes since there are two market failures (inefficient waste recycling and overconsumption of waste generating products) but only one policy instrument. However, when countries coordinate policy instruments, EPR recycling targets can be combined with either excise duties or taxes on recycling residuals to achieve the social optimum. In the noncooperative scenario, strategic behaviour may lead to a 'race to the bottom' for taxes on recycling residuals or to a 'race to the top' for excise duties and EPR recycling targets.

Eichner and Pethig (2015) question whether there are convincing welfare economic arguments in favour of a subsidy on green energy that complements a carbon emission trading scheme. Hence, they explain the coexistence of both policy instruments as the outcome of a lobbying game, taking emission trading as given. They consider three lobbying groups: a brown lobby, a green lobby and a consumer lobby. If the brown lobby is stronger than the green lobby, they show that green consumer preferences are a necessary condition for a green subsidy as an equilibrium outcome.

Environmental tax systems often have to rely on self-reported emissions by firms, which are verified through costly auditing mechanisms. Oestreich (2015) compares three audit mechanisms with respect to the generated emission levels and the underlying incentives for truthful reporting: a random audit mechanism (RAM) (which is mostly assumed in the literature) and two competitive audit mechanisms (CAM) (imperfectly or perfectly discriminating audit mechanisms, respectively). In particular, it is shown that the imperfectly discriminatory 
CAM may induce fewer emissions than RAM. However, the CAM with perfect discrimination may induce higher emissions than RAM.

\section{References}

Álvarez A, Andre FJ (2015) Auctioning vs. grandfathering in cap-and-trade systems with market power and incomplete information. Environ Resour Econ. doi:10.1007/s10640-014-9839-z

Bayramoglu B, Jacques JF (2015) International environmental agreements: the case of costly monetary transfers. Environ Resour Econ. doi:10.1007/s10640-014-9837-1

Boucher V, Bramoullé Y (2010) Providing global public goods under uncertainty. J Public Econ 94:591-603

Bramoullé Y, Treich N (2009) Can uncertainty alleviate the commons problem? J Eur Econ Assoc 7(5):10421067

Braulke M, Endres A (1985) On the economics of effluent charges. Can J Econ 18:891-897

Carraro C, Marchiori C, Oreffice S (2009) Endogenous minimum participation in international environmental treaties. Environ Resour Econ 42:411-425

Dubois M, Eyckmans J (2015) Efficient waste management policies and strategic behavior with open borders. Environ Resour Econ. doi:10.1007/s10640-014-9851-3

Eichner T, Pethig R (2015) Lobbying for and against subsidizing green energy. Environ Resour Econ. doi:10. 1007/s10640-014-9852-2

Endres A (1976) Die pareto-optimale Internalisierung externer Effekte. Lang, Frankfurt, Bern

Endres A (1977a) Nonseparability and the voluntary approach to externality problems. J Environ Econ Manag 4:209-213

Endres A (1977b) Die Coase-Kontroverse. J Inst Theor Econ 133:637-651

Endres A (1980) Second hand markets and the private supply of excludable public goods. Public Finance 35:227-238

Endres A (1983) Do effluent charges (slways) reduce environmental damage? Oxf Econ Pap 35:254-261

Endres A (1985) Environmental policy with pollutant interactions. In: Pethig R (ed) Public goods and public allocation policy. Bern/Frankfurt/New York, pp 165-199

Endres A (1986) Charges, permits and pollutant interactions. Eastern Econ J 12:327-336

Endres A (1989) Liability and information. J Inst Theor Econ 145:249-274

Endres A (1991a) The economics of accident law. Public Finance 46:198-207

Endres A (1991b) Ökonomische Grundlagen des Haftungsrechts. Physica, Heidelberg

Endres A (1992) Strategic behavior under tort law. Int Rev Law Econ 12:377-380

Endres A (1997) Negotiating a climate convention-the role of prices and quantities. Int Rev Law Econ $17: 147-156$

Endres A (2011) Environmental economics-theory and policy. Cambridge University Press, Cambridge

Endres A, Bertram R (2006) The development of care technology under liability law. Int Rev Law Econ 26:503-518

Endres A, Bertram R, Rundshagen B (2007) Environmental liability law and induced technical change- the role of discounting. Environ Resour Econ 36:341-366

Endres A, Finus M (1998a) Renegotiation-proof equilibria in a bargaining game over global emission reductions - does the instrumental framework matter? In: Hanley N, Folmer H (eds) Game theory and the global environment. Edward Elgar, Cheltenham, UK, ch. 7, pp 135-164

Endres A, Finus M (1998b) Playing a better global warming game: does it help to be green? Swiss J Econ Stat 134:21-40

Endres A, Finus M (1999) International environmental agreements: how the policy instrument affects equilibrium emissions and welfare. J Inst Theor Econ 155:527-550

Endres A, Finus M (2002) Quotas may beat taxes in a global emission game. Int Tax Public Finance 9:687-707

Endres A, Friehe T (2011) Incentives to diffuse advanced abatement technology under environmental liability law. J Environ Econ Manag 62:30-40

Endres A, Friehe T (2012) Market power in the eco-industry: polluters' incentives under environmental liability law. Land Econ 88:121-138

Endres A, Friehe T (2015) The compensation regime in liability law: incentives to curb environmental harm, ex ante and ex post. Environ Resour Econ. 62:105-123

Endres A, Lüdeke A (1998) Limited liability and imperfect information—on the existence of safety equilibria under products liability law. Eur J Law Econ 5:153-165

Endres A, Lüdeke A (1999) Incomplete strict liability—effects on products differentiation and information provision. Int Rev Law Econ 18:511-528 
Endres A, Ohl C (2002) Introducing "Cooperative Push": how inefficient environmental policy (sometimes!) protects the global commons better. Public Choice 111:285-302

Endres A, Ohl C (2003) International environmental cooperation with risk aversion. Int J Sustain Dev 6:378392

Endres A, Querner I (1995) On the existence of care equilibria under tort law. J Inst Theor Econ 151:348-357

Endres A, Rundshagen B (2010) Standard oriented environmental policy — cost effectiveness and incentives for 'Green Technology'. Ger Econ Rev 11:86-107

Endres A, Rundshagen B (2013) Incentives to diffuse advanced abatement technology under the formation of international environmental agreements. Environ Res Econ 56:177-210

Finus M (2001) Game theory and international environmental cooperation. Edward Elgar, Cheltenham, UK

Finus M, Rundshagen B (1998a) Renegotiation-proof equilibria in a global emission game when players are impatient. Environ Res Econ 12:275-306

Finus M, Rundshagen B (1998b) Toward a positive theory of coalition formation and endogenous instrumental choice in global pollution control. Public Choice 96:145-186

Gomes A (2005) Multilateral contracting with externalities. Econometrica 73:1329-1350

Heuson C, Peters W, Schwarze R, Topp AK (2015) Investment and adaptation as commitment devices in climate politics. Environ Resour Econ. doi:10.1007/s10640-015-9887-z

Hong F, Karp L (2013) International environmental agreements with exogenous and endogenous risk. Mimeo, New York

Houba H, van der Laan G, Zeng Y (2015) International environmental agreements for river sharing problems. Environ Resour Econ. doi:10.1007/s10640-014-9862-0

Hovi J, Ward H, Grundig F (2015) Hope or despair? Formal models of climate cooperation. Environ Resour Econ. doi:10.1007/s10640-014-9799-3

Jacob J (2015) Innovation in risky industries under liability law: the case of "Double-impact" Innovations. J Inst Theor Econ. doi:10.1628/093245615

Korsmo CR (2015) The reasonable person standard: a new perspective on the incentive effects of a tailored negligence standard. Eur J Law Econ. Published online. doi:10.1007/s10657-015-9487-y

Kuosmanen T, Laukkanen M (2011) (In)Efficient environmental policy with interacting pollutants. Environ Res Econ 48:629-649

Lessmann K, Kornek U, Bosetti V, Dellink R, Emmerling J, Eyckmans J, Nagashima M, Weikard HP, Yang Z (2015) The stability and effectiveness of climate coalitions: a comparative analysis of multiple integrated assessment models. Environ Res Econ. doi:10.1007/s10640-015-9886-0

McEvoy DM, Cherry TL, Stranlund JK (2015) Endogenous minimum participation in international environmental agreements: an experimental analysis. Environ Resour Econ. doi:10.1007/s10640-014-9800-1

Ochea MI, de Zeeuw A (2015) Evolution of reciprocity in asymmetric international environmental negotiations. Environ Resour Econ. doi:10.1007/s10640-014-9841-5

Oestreich AM (2015) Firms' emissions and self-reporting under competitive audit mechanisms. Environ Resour Econ. doi:10.1007/s10640-014-9855-z

Pintassilgo P, Kronbak LG, Lindroos M (2015) International fisheries agreements: a game theoretical approach. Environ Resour Econ. doi:10.1007/s10640-014-9850-4

Stephan G, Müller-Fürstenberger G (2015) Global warming, technological change and trade in carbon energy: challenge or threat? Environ Resour Econ. doi:10.1007/s10640-014-9818-4

Weikard HP, Wangler L, Freytag A (2015) Minimum participation rules with heterogeneous countries. Environ Resour Econ. doi:10.1007/s10640-014-9861-1 